\title{
The use of fluorinated CNTs as epoxy resin modifiers
}

\author{
Alexander N. Blohin ${ }^{1, *}$, Tatiana P. Dyachkova ${ }^{1}$, and Artem K. Sukhorukov ${ }^{1}$ \\ ${ }^{1}$ Tambov State Technical University, Sovetskaya street, 106, Tambov, 392000, Russia
}

\begin{abstract}
The effect of fluorination conditions for carbon nanotubes (CNTs) on their chemical composition and structure was studied by IR-Fourier, X-ray photoelectron and Raman spectroscopy, X-ray diffraction analysis, thermogravimetry and electron microscopy. The CNT treatment using fluorine does not cause noticeable damages to side walls and a pronounced increase in the degree of defectiveness, but contributes to an increase of up to 2.26 times in the specific surface area. From the viewpoint of a reinforcing effect, when introduced into a polymer matrix based on a Bisphenol-F-type epoxy resin, the fluorinated CNTs are noticeably more effective than the initial ones. At the fluorinated CNT concentration of $0.1 \mathrm{wt} . \%$ in the composite, the tensile strength, Young's modulus at stretching, flexural strength and Young's modulus at bending increase by 50,74, 60 and $66 \%$, respectively, whereas the thermal stability and electrical conductivity of the composite practically do not change.
\end{abstract}

\section{Introduction}

Recently, carbon nanomaterials, especially single-walled and multi-walled carbon nanotubes (CNTs), have been widely used as fillers to improve the properties of polymer composites [1]. In many cases, the tendency of CNTs to agglomerate, low polarity of their surface, and low adhesion to polymer matrices do not allow for achieving the necessary efficiency indicators [2-12]. To enhance the affinity of the fillers to polymers and solvents, various methods of plasma, chemical and mechanical processing are used. One of the most promising ways of functionalizing the CNT surface is direct fluorination using treatment with fluorine gas at elevated temperature [13-17].

In this regard, the purpose of the present work was to study the effect of fluorination conditions on the chemical composition and structural characteristics of CNTs and the strength characteristics of composites based on a Bisphenol-F-type resin modified with initial and fluorinated CNTs.

\section{Experimental}

After fluorinating the CNTs, a broad diffuse band appears at $1200 \mathrm{~cm}-1$ in the IR spectra (Fig. 1) due to the presence of covalent C-F bonds [1-2], and the intensity of bands in the range of $1720-1550 \mathrm{~cm}-1$ increases, which is apparently caused by the availability of carboxyl groups formed during the fluorination due to the technological impurity of oxygen in fluorine, as reported elsewhere for similar processes of polymer fluorination [1-2].

Another reason may be production of surface defects with increasing process temperature. The nature of the IR spectra changes shows an increase in the number of C-F bonds formed with increasing the duration and temperature of the CNT treatment using fluorine. It was noted that the areas of the bands at $1200 \mathrm{~cm}-1$ for the CNT samples subjected to fluorination for $2 \mathrm{~h}$ at 150 and $250^{\circ}$ $\mathrm{C}$ are approximately the same. However, at a higher temperature, more "defective" oxygen-containing groups are formed on the CNT surface.

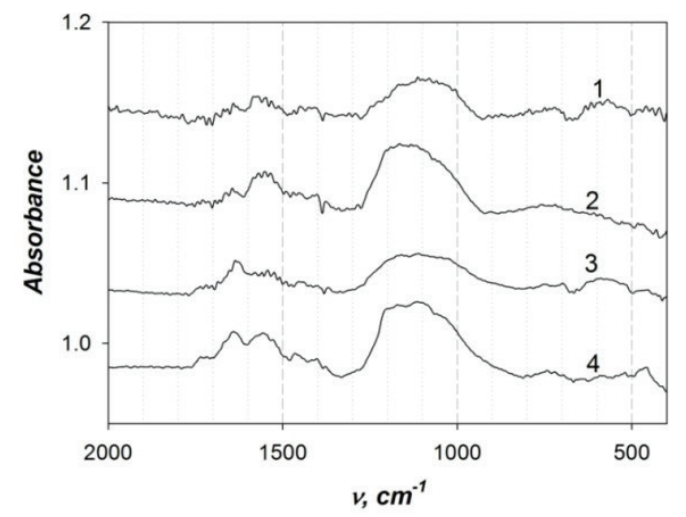

Fig. 1. IR spectra of the initial (1) and fluorinated (2-4) CNTs. Fluorination was carried out by treating the CNTs with undiluted fluorine at a fluorine pressure of 0.7-0.8 atm. Fluorination temperature $\left({ }^{\circ} \mathrm{C}\right)$ and treatment time: $150{ }^{\circ} \mathrm{C}$ and $2 \mathrm{~h} \mathrm{(2),} 150^{\circ} \mathrm{C}$ and $10 \mathrm{~min}(3)$, and $250^{\circ} \mathrm{C}$ and $2 \mathrm{~h}$ (4).

According to the X-ray photoelectron spectroscopy data, the initial samples include $2 \%$ of atmospheric oxygen. After the direct fluorination at a pressure of 0.7 $\mathrm{atm}$ and a temperature of $150 \mathrm{oC}$ for $2 \mathrm{~h}$, the ratio of the atomic fractions of carbon, oxygen and fluorine is $78: 1.3$ : 20.7. Consequently, the atomic ratio of $\mathrm{F} / \mathrm{C}$ was 0.265 . In the case of formation of chemical bonds between carbon and fluorine, the type of the C1s-spectrum of carbon

\footnotetext{
* Corresponding author: cha-cha@,rambler.ru
} 
changes as the fluorine concentration increases (Fig. 2). In that spectrum, several absorption bands can be distinguished at the formation energy of 284.5 (1), 286.2 (2), 288.1 (3), and 289.1 (4) eV. Peak 1 corresponds to a signal from carbon atoms coordinated only by carbon.

Comparing the reference [3-4] data with the data obtained herein, the remaining peaks may be interpreted as follows (Fig. 2):

-peak 4 corresponds to the carbon, which has one bond with fluorine $(\mathrm{C}-\mathrm{F})$, the other three bonds are carboncarbon $\left(\mathrm{C}-\mathrm{C}^{*}\right)$, where $\mathrm{C} *$ is carbon having one bond with the fluorine. This indicates the transformation of the sp2hybridization of the atoms of the initial CNTs into the sp3hybridized state, since all four bonds of the carbon atom are implemented;

-peak 3 corresponds to the carbon atom, in which one bond is occupied by the fluorine, the other two - by the carbon $\mathrm{C} *$ having one bond with the fluorine;

-peak2 corresponds to the carbon atom not directly bound to the fluorine, but having three or four $\mathrm{C}-\mathrm{C}$ * bonds. If one assumes the presence of four bonds, then the appearance of the fourth bond is possible when disclosing the bond of the sp2-hybridized atom and the formation of the sp3-hybridized bond with the neighboring atom.

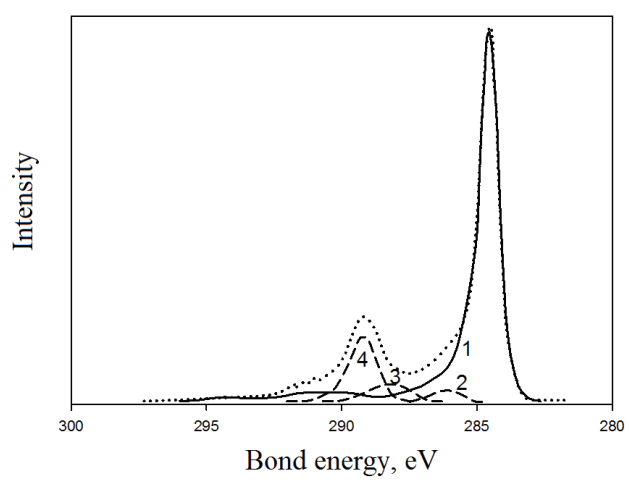

Fig. 2. X-ray photoelectron spectra obtained for the initial CNTs (continuous line) and the CNTs fluorinated at $150 \mathrm{oC}$ CNT (1, dotted line). 2, 3 and 4 are the lines distinguished during the fitting for the fluorinated CNTs. The total spectrum of the fitting is not shown in the figure, since it practically coincides with the spectrum experimentally measured within the line thickness.

The formation of the "fluorine-carbon" bonds has the following peculiarity. They are formed by specific "islets", meaning that the carbon atom is bound to the fluorine atom surrounded by the similar atoms bound to F. The localization of such "islets" is due to the presence of defective sites on the surface of the initial CNTs.

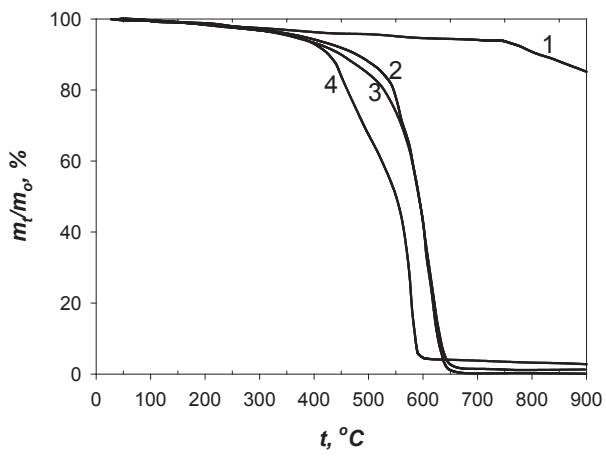

Fig. 3. Thermogravimetric data obtained in argon medium for the initial (1) and fluorinated (2-4) CNTs. Fluorination performed by treatment using undiluted F2 at 0.7-0.8 atm. Temperature and processing time: $150^{\circ} \mathrm{C}$ and $2 \mathrm{~h}(2), 150^{\circ} \mathrm{C}$ and $10 \mathrm{~min}(3)$, and $250^{\circ} \mathrm{C}$ and $2 \mathrm{~h} \mathrm{(4).}$

According to the thermo gravimetric data (Fig. 3), the thermal stability of the initial and fluorinated CNTs at temperatures up to $300-350{ }^{\circ} \mathrm{C}$ does not practically differ, and at higher temperatures the functionalized CNTs are less stable, which is associated with the dissociation of the $\mathrm{C}-\mathrm{F}$ bonds. The CNTs treated with the fluorine at $250{ }^{\circ} \mathrm{C}$ (curve 4 in Fig. 3) undergo degradation at a temperature lower than for the CNTs processed at $150^{\circ} \mathrm{C}$ (curves 2-3 in Fig. 3), which is obviously associated with a higher degree of defectiveness.

The effect of the fluorination on the structure and degree of defectiveness was investigated by Raman spectroscopy, transmission electron microscopy (TEM), and X-ray diffraction analysis. The Raman spectra (Fig. 4) and X-ray diffraction patterns of the initial and fluorinated CNTs differ a little from each other, thereby indirectly confirming the previously expressed opinion that after the fluorination, the formation of "carbonfluorine" bonds occurs at sites of primary defects of the CNT side walls, and no new defects take place.

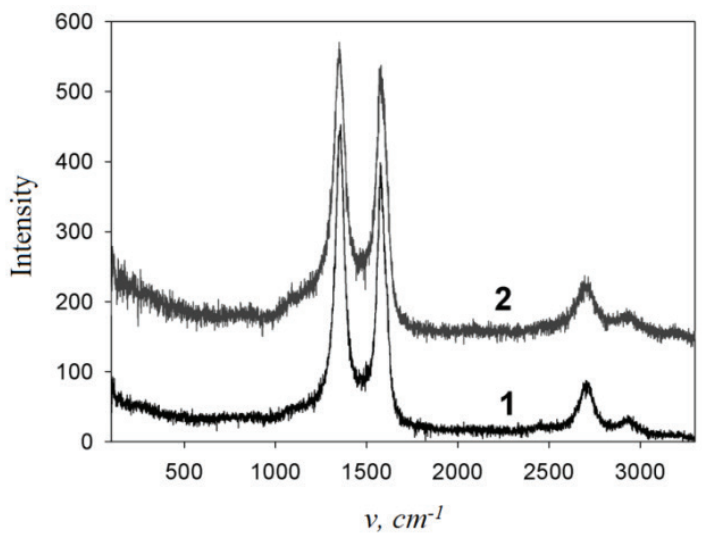

Fig. 4. Raman spectra obtained for the CNTs: initial (1) and fluorinated at $150{ }^{\circ} \mathrm{C}(2)$. 


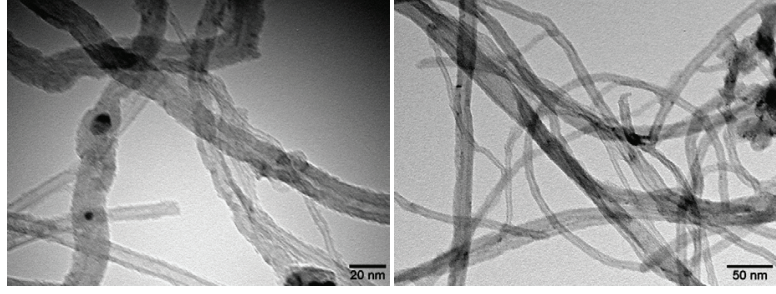

Fig. 5. TEM images of the CNTs fluorinated at $150{ }^{\circ} \mathrm{C}$.

During fluorination, the CNT specific surface area increases (Table 1). The greatest increase, 2.26-fold, was recorded for the sample treated at $150{ }^{\circ} \mathrm{C}$. Increasing the fluorination temperature to $250{ }^{\circ} \mathrm{C}$ or introducing the oxygen into the fluorinating mixture gives a lesser effect. The increase in the specific surface area during the fluorination can positively affect the strengthening effect of the CNTs when incorporating them into the epoxy composition.

Thus, the samples fluorinated at $150{ }^{\circ} \mathrm{C}$ have the same degree of fluorination as the CNTs fluorinated at $250{ }^{\circ} \mathrm{C}$, but have a higher specific surface area and fewer defects. Based on the data obtained, it can be assumed that the reinforcing effect of the CNTs fluorinated at $150{ }^{\circ} \mathrm{C}$ will be maximum, and further on, to strengthen epoxy composites, these CNTs were used.

Table 1. The fluorination effect on the specific surface area of the "Taunit-M" CNTs. The pressure of the fluorinating mixture is $0.7 \mathrm{~atm}$, and the fluorination time is $2 \mathrm{~h}$.

\begin{tabular}{|c|c|c|c|}
\hline Sample & $\begin{array}{c}\text { Fluorination } \\
\text { mixture }\end{array}$ & $\begin{array}{c}\text { Fluorination } \\
\text { temperature, } \\
\mathbf{C}\end{array}$ & $\begin{array}{c}\text { Specific } \\
\text { surface area, } \\
\mathbf{m}^{2} / \mathbf{g}\end{array}$ \\
\hline $\begin{array}{c}\text { Initial } \\
\text { CNTs }\end{array}$ & - & - & 105 \\
\hline $\begin{array}{c}\text { Fluorinated } \\
\text { CNTs }\end{array}$ & $\mathrm{F}_{2}$ & 250 & 166 \\
\hline $\begin{array}{c}\text { Fluorinated } \\
\text { CNT }\end{array}$ & $80 \% \mathrm{~F}_{2}+20 \% \mathrm{O}$ & 150 & 180 \\
\hline $\begin{array}{c}\text { Fluorinated } \\
\text { CNT }\end{array}$ & $\mathrm{F}_{2}$ & 150 & 238 \\
\hline
\end{tabular}

Both the initial and fluorinated CNTs were firstly dispersed directly in the epoxy resin, due to shear flows in a thin gap between rotating rolls, and then sonicated in a thin layer

The dispersion composition of the obtained materials was studied on a Nicomp 308ZLS instrument by the dynamic light scattering method, which makes it possible to estimate the effective particle size of the disperse phase, which would be a true size if these particles were spherical.

Since both the CNTs and the agglomerates formed by them are not spherical, the results of the measurements allow for evaluating only relative changes in the disperse composition of the suspensions analyzed.

As seen from the analysis of the particle effective size distribution diagram (Fig. 6), the suspension containing the initial CNTs is polydisperse. The average effective size of the smallest agglomerates was found to be $418 \mathrm{~nm}$. The second peak shows an effective particle size of about $7 \mu \mathrm{m}$, and the number of large agglomerates slightly dominates over the number of smaller ones.
The suspension containing the fluorinated CNTs is monodisperse, and the average effective agglomerate size was found to be about $900 \mathrm{~nm}$, and larger agglomerates cannot be observed. Thus, the CNT fluorination contributes to a better dispersion of these in the epoxy binder.

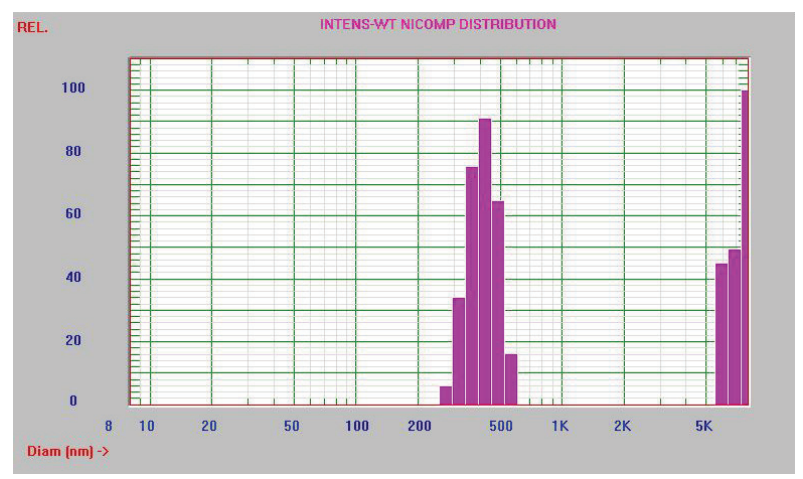

$\mathrm{a}$

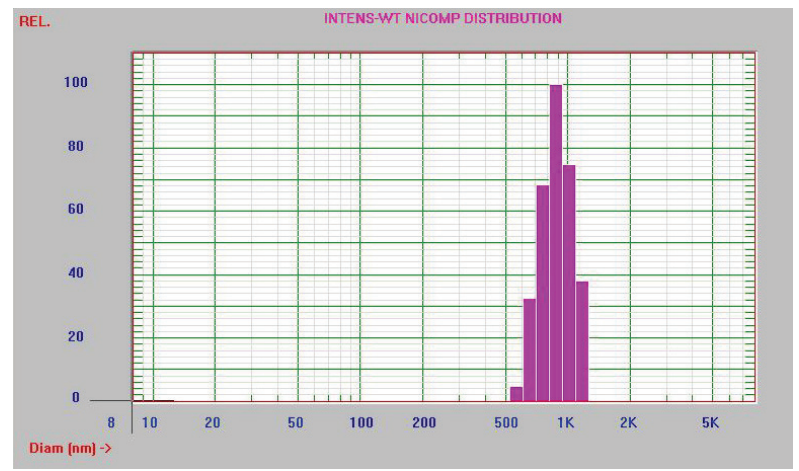

b

Fig. 6. Effective size distribution of the initial (a) and fluorinated (b) CNTs in the BFE-170 epoxy monomer dissolved in isopropyl alcohol. CNT concentration - 0.1 wt.\%.

The use of the CNTs leads to a significant increase in the mechanical characteristics of the epoxy composites (Bisphenol-F-type resin and L-19 polyaminoamide-based hardener) on the basis thereof (Table 2, Figs. 7-8).

The fluorinated CNTs provide better effect compared with the initial ones. The greatest effect is achieved with 0.1 wt. $\%$ of the fluorinated CNTs in the composite: the tensile strength increases by $50 \%$, the Young's modulus at stretching increases by $74 \%$, the flexural strength increases by $60 \%$, and the Young's modulus at bending increases by $66 \%$. As can be seen from Figs. 7-8, the results obtained after studying the effect on the tensile and flexural strength and the corresponding moduli (in percent), are superior to the literature data obtained using unmodified single- and multi-walled CNTs, aminofunctionalized, oxidized and fluorinated CNTs, grafted epoxy groups, and nano-polyaniline [5,13-18].

Only in one of the above mentioned papers [16], the same increase in the tensile strength as in the experiments described herein, is reported; however, the amount of multi-walled amino-functionalized nanotubes introduced into the epoxy composition is $1 \%$. In our experiments, the 
same effect was achieved at the fluorinated CNT concentration of $0.1 \%$, i.e., 10 times less than in [16].

Table 2. Mechanical properties of the epoxy composites

\begin{tabular}{|c|c|c|c|c|c|}
\hline $\begin{array}{c}\text { Concentrati } \\
\text { on of CNTs } \\
\text { introduced } \\
\text { into the } \\
\text { composite, } \\
\text { wt.\% }\end{array}$ & $\begin{array}{c}\text { Tensile } \\
\text { strength, } \\
\text { MPa }\end{array}$ & $\begin{array}{c}\text { Young' } \\
\text { S } \\
\text { modulu } \\
\text { s, MPa }\end{array}$ & $\begin{array}{c}\text { Breakig } \\
\text { elongati } \\
\text { on, \% }\end{array}$ & $\begin{array}{c}\text { Flexura } \\
\text { strengt } \\
\text { h, MPa }\end{array}$ & $\begin{array}{c}\text { Young' } \\
\text { S } \\
\text { modulu } \\
\text { s, MPa }\end{array}$ \\
\hline $\begin{array}{c}\text { (unfilled } \\
\text { composite) }\end{array}$ & $18.2 \pm 1.09$ & $849 \pm 51$ & $4.3 \pm 0.22$ & $32 \pm 1.60$ & $933 \pm 47$ \\
\hline $\begin{array}{c}0.01 \% \\
\text { of initial } \\
\text { CNTs }\end{array}$ & $20 \pm 1.1$ & $1077 \pm 44$ & $4.2 \pm 0.2$ & $42 \pm 1.7$ & $1100 \pm 55$ \\
\hline $\begin{array}{c}0.1 \% \\
\text { of initial } \\
\text { CNTs }\end{array}$ & $24 \pm 1.2$ & $1137 \pm 46$ & $4.9 \pm 0.2$ & $45 \pm 1.8$ & $1251 \pm 50$ \\
\hline $\begin{array}{c}0.5 \% \\
\text { of initial } \\
\text { CNTs }\end{array}$ & $23 \pm 1.1$ & $1245 \pm 50$ & $4 \pm 0.16$ & $43 \pm 1.7$ & $1290 \pm 52$ \\
\hline $\begin{array}{c}0.01 \% \\
\text { of fluorinated } \\
\text { CNTs }\end{array}$ & $22 \pm 0.88$ & $1352 \pm 54$ & $4 \pm 0.15$ & $45 \pm 1.75$ & $1187 \pm 48$ \\
\hline $\begin{array}{c}0.1 \% \\
\text { of fluorinated } \\
\text { CNTs }\end{array}$ & $27 \pm 1.05$ & $1479 \pm 56$ & $3.5 \pm 0.14$ & $51 \pm 2.0$ & $1550 \pm 59$ \\
\hline $\begin{array}{c}0.5 \% \\
\text { of fluorinated } \\
\text { CNTs }\end{array}$ & $25 \pm 1.0$ & $1588 \pm 65$ & $3.2 \pm 0.13$ & $48 \pm 1.8$ & $1611 \pm 61$ \\
\hline
\end{tabular}
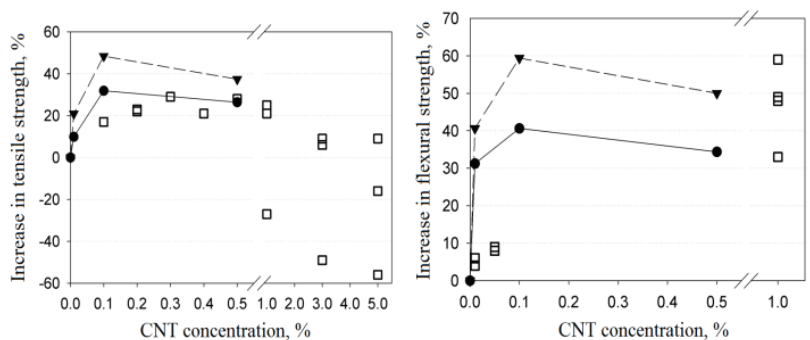

Fig. 7. Dependences of the increase in the tensile and flexural strength on the concentration of the initial (circles, continuous curve) and fluorinated (triangles, dashed curve) CNTs (wt.\%). Unfilled squares refer to literature data on hardening using various nanomaterials [5,13-17].
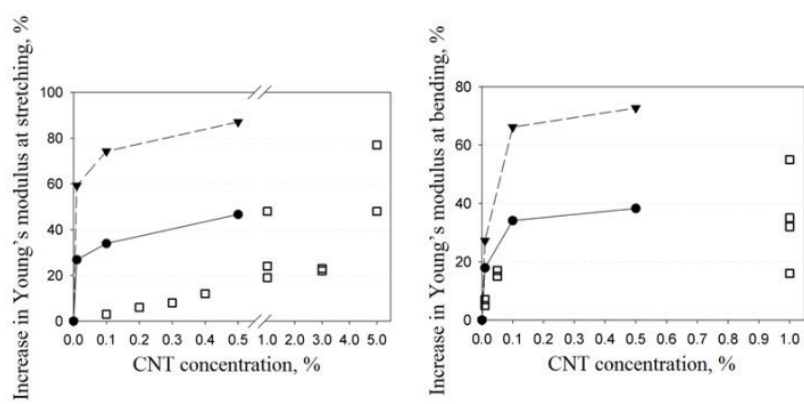

Fig. 8. Dependences of the increase in the Young's modulus at stretching and bending on the concentration of the initial (circles, continuous curve) and fluorinated (triangles, dashed curve) CNTs (wt.\%). Unfilled squares refer to literature data [5,13-17].

According to the TGA data, the unfilled composites based on the Bisphenol-F-type resin begin to collapse at about $300{ }^{\circ} \mathrm{C}$ (1, Fig. 9). The introduction of the initial
CNTs results in a significant decrease in the thermal stability of the composite (2, Fig. 9). On the contrary, the availability of the fluorinated CNTs in the composite practically does not lead to a deterioration of the thermal stability of the composite (3, Fig. 9) at temperatures up to $300{ }^{\circ} \mathrm{C}$, very slightly degrades the thermal stability in the range of $300-370^{\circ} \mathrm{C}$, and slightly improves it in the range of $380-430{ }^{\circ} \mathrm{C}$.

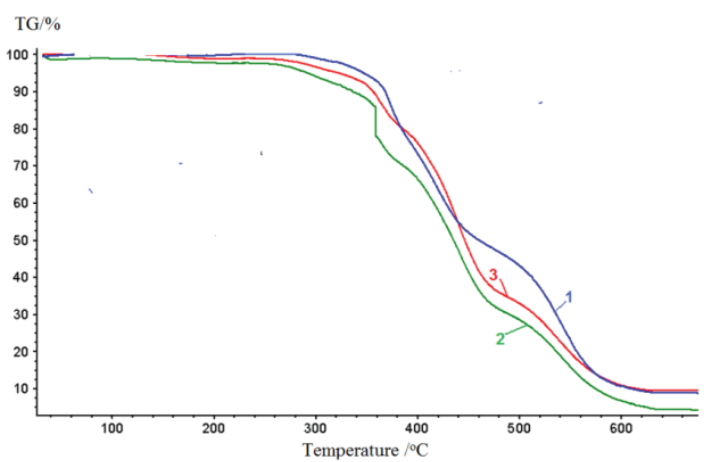

Fig. 9. TGA data obtained in air medium for the epoxy composites: (1), filled with 0.1 wt.\% of the initial CNTs (2), and filled with $0.1 \mathrm{wt} . \%$ of the fluorinated CNTs (3).

The results on the measurement of the electrical resistivity of the composites are given in Table. 3 . In the percentage region of up to $0.5 \mathrm{wt}$. $\%$, the CNTs cause to a decrease in the resistivity of the epoxy bisphenol matrix from 274 to $6 \mathrm{MOhm} . \mathrm{m}$. The introduction of the fluorinated CNTs does not lead to an improvement in the electrical conductivity of the epoxy bisphenol matrix, and the composite remains insulator.

Table 3. The effect of the CNT additive on the resistivity of the epoxy composite.

\begin{tabular}{|c|c|c|c|c|c|c|}
\hline & \multicolumn{3}{|c|}{ Initial CNTs } & \multicolumn{3}{c|}{ Fluorinated CNTs } \\
\hline $\begin{array}{c}\text { Concentratio } \\
\text { n of CNTs } \\
\text { introduced } \\
\text { into the } \\
\text { epoxy matrix }\end{array}$ & $0.01 \%$ & $0.1 \%$ & $0.5 \%$ & $0.01 \%$ & $0.1 \%$ & $0.5 \%$ \\
\hline Resistivity & $\begin{array}{c}274 \\
\mathrm{MOh} \\
\mathrm{m} \mathrm{m}\end{array}$ & $\begin{array}{c}\mathrm{MOh} \\
\mathrm{m} \mathrm{m}\end{array}$ & $\begin{array}{c}6 \\
\mathrm{MOh} \\
\mathrm{m} \mathrm{m}\end{array}$ & $\begin{array}{c}\text { GOh } \\
\mathrm{m} \mathrm{m}\end{array}$ & $\begin{array}{c}\mathrm{GOh} \\
\mathrm{m} \mathrm{m}\end{array}$ & $\begin{array}{c}\mathrm{GOh} \\
\mathrm{m} \mathrm{m}\end{array}$ \\
\hline
\end{tabular}

The analysis of the SEM images presented in Figs. 1012 shows that the rupture surfaces of all the composites have a structure close to each other, independent of the presence or absence of the initial and fluorinated CNTs.

For the filled composites, the CNTs were not found on the rupture surface, which may be explained by fairly good adhesion of both the initial and fluorinated CNTs to the epoxy matrix. This statement lies in agreement with the fact that these CNTs harden the polymer composition at the concentration of $0.1 \%$ (Fig. 7). However, it can be emphasized once again that the fluorinated CNTs are more effective for hardening the polymer composition than the initial ones. 


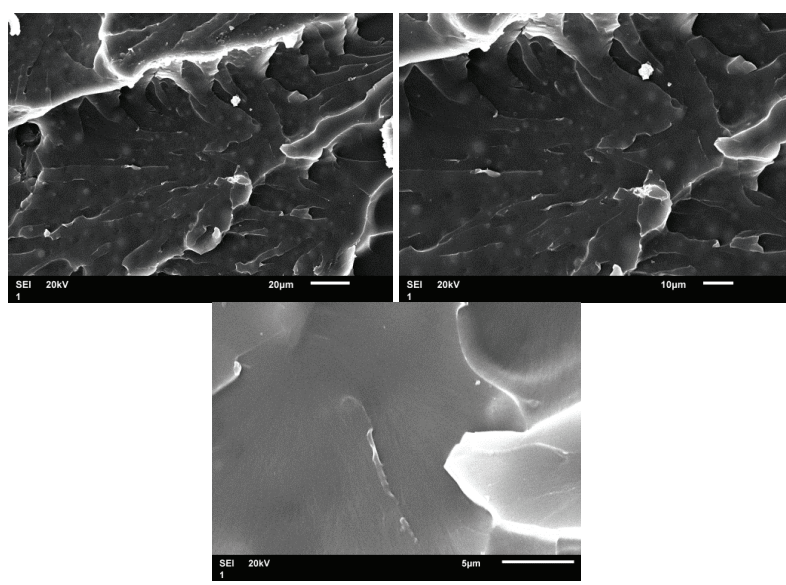

Fig. 10. SEM images of rupture surfaces of the unfilled composite.

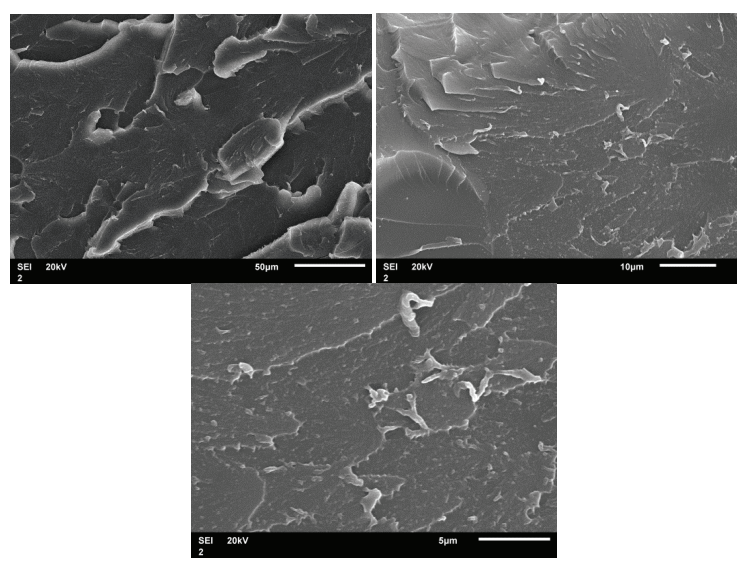

Fig. 11. SEM images of rupture surfaces of the composite containing 0.1 wt. $\%$ of the initial CNTs.
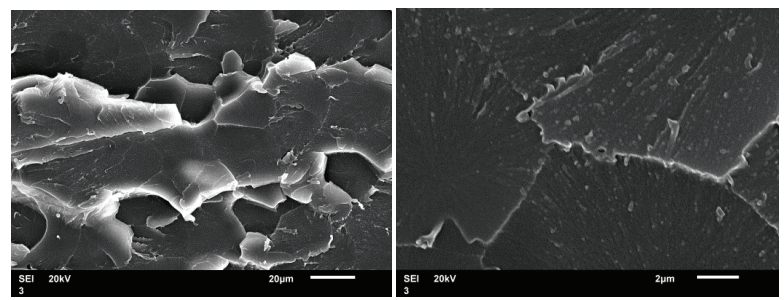

Fig. 12. SEM images of rupture surfaces of the composite containing 0.1 wt. $\%$ of the fluorinated CNTs.

\section{Conclusion}

Both the initial and fluorinated CNTs can be effectively used for hardening epoxy resin composites when their concentration in those materials is about $0.1 \mathrm{wt} . \%$. The tensile and flexural strength and Young's modulus are significantly improved. The fluorinated CNTs are more effective as fillers compared with the initial ones.

This was confirmed by mechanical tests and electron microscopy analyses. Owing to the increase in the CNT specific surface area during the fluorination and formation of polar functional groups, the adhesion between the matrix (epoxy resin) and the filler is increased, thereby contributing to the improvement in the mechanical properties of the composites.
In this regard, the CNTs treated with fluorine at 150 ${ }^{\circ} \mathrm{C}$ are the most efficient. An increase in the fluorination temperature reduces the strengthening effect of the CNTs, which may be due to damages of their surface

The achieved tensile strength and flexural strength of the epoxy composites based on the "Bisphenol-F"-type epoxy resin reinforced with the fluorinated CNTs significantly exceeds the available literature data for similar materials when the CNT concentration is less than 5 wt.\%. The fluorinated CNTs used as fillers did not degrade the thermal stability of the composites and did not affect the dielectric properties.

The research was funded by the Russian Science Foundation under Grant No. 15-13-10038.

\section{References}

1. Y.-S. Lee. T.H. Cho. B.K. Lee. J.S. Rho. K.H. An. Y.H. Lee, Surface properties of fluorinated singlewalled carbon nanotubes,J. Fluorine Chem, 120 (2003)

2. G. Socrates, Infrared Characteristic Group Frequences $^{\beta r d}$ edition, Chichester (N.Y.; Brisbane; Weinheim, Toronto, Brisbane, Singapore: John Wiley \& Sons, 2001)

3. J.-M. Lee, S.J. Kim, J.W. Kim, P.H. Kang, Y.C. Nho, Y.-S. Lee, A high resolution XPS study of sidewall functionalized MWCNTs by fluorination, J. Industr. Engng. Chem., 15 (2009)

4. I. Crassous, H. Groult, F. Lantelme, D. Devilliers, A. Tressaud, C. Labrugere, M. Dubois et al., Study of the fluorinationof carbon anode in molten $K F-2 H F$ by XPS and NMR investigations, J. Fluorine Chem., 130 (2009).

5. X. Zhang, Q. He, H. Gu, H.A. Colorado, S. Wei, Z. Guo, Flame-etardant Electrical Conductive Nanopolymers Based on Bisphenol F Epoxy Resin Reinforced with Nano Polyanilines, ACS Appl. Mater. Interfaces., V. 5, P. 898-910 (2013)

6. M. Moniruzzaman, F. Du, N. Romero, K.I. Winey, Increased flexural modulus and strength in SWNT/epoxy composites by a new fabrication method, Polymer 47 (2006)

7. Zhengtao Yang, K. McElrath, J. Bahr, N.A. D'Souza, Effect of matrix glass transition on reinforcement efficiency of epoxy-matrix composites with single walled carbon nanotubes, multi-walled carbon nanotubes, carbon nanofibers and graphite, Composites: Part B. 43 (2012)

8. R. Chaos-Moran, A. Salazar, A. Urena, Mechanical Analysis of Carbon Nanofiber/Epoxy Resin Composites, Polymer Comp. 32 (2011)

9. Y. Zhou, F. Pervin, S. Jeelani et al., Improvement in mechanical properties of carbon fabric-epoxy composite using carbon nanofibers, J. Mater. Processing Technol. 198 (2008)

10. Schulte. Influence of different carbon nanotubes on the mechanical properties of epoxy matrix 
composites - A comparative study, Comp. Sci. Techn. 65 (2005)

11. L.Q. Liu, H.D. Wagner, Rubbery and glassy epoxy resins reinforced with carbon nanotubes, Comp. Sci. Techn. 65 (2005)

12. G.S. Baronin, D.V. Pugachev, D.E. Kobzev, P.V. Kombarova, Investigation of strength properties and impact viscosity of ceramic polymeric composites based on abs-copolymer and uhmwpe, liquid and solid-phase extrusion, Bulletin of TSTU. 17 (2011)

13. R.G. de Villoria, A. Miravete, J. Cuartero, A. Chiminelli, N. Tolosana, Mechanical properties of SWNT/epoxy composites using two different curing cycles, Composites Part B: Engng. 37 (2006)

14. Z. Wanga, H.A. Colorado, Z.-H. Guo, H. Kim, C.-L. Park, H. T. Hahna, S.-G. Lee, K.-H. Lee, Y.-Q. Shang, Effective Functionalization of Carbon Nanotubes for Bisphenol F Epoxy Matrix Composites, Materials Research. 15 (2012)

15. D.H. Wang, S. Sihn, A.K. Roy, J.-B. Baek, L.-S. Tan, Nanocomposites based on vapor-grown carbon nanofibers and an epoxy: Functionalization, preparation and characterization, Europen Polymer J. 46 (2010)

16. Y. Zhou, F. Pervin, L. Lewis, S. Jeelani, Experimental study on the thermal and mechanical properties of multiwalled carbon annotubereinforced epoxy, Materials Sci. Engng. 452 (2007)

17. M. Theodore, M. Hosur, J. Thomas, S. Jeelani, Characterization of epon 862 reinforced withfunctionalized,

MCNT's// http://www.iccmcentral.org/Proceedings/I CCM16proceedings/ contents/pdf/MonA /MoAA201sp_theodorem222779p.pdf

18. I.V. Anosova, M.O. Telegin, Development of technology of modification of cht series "Taunit" by polyaniline. Problems of technogenic security and sustainable development: Sat. sci. art. young scientists, graduate students and students, TSTU, 4 (2013) 